\title{
In Vivo Voltammetric Monitoring of Catecholamine Release in Subterritories of the Nucleus Accumbens Shell
}

\author{
Jinwoo Park ${ }^{1}$, Brandon J. Aragona1,2, Brian M. Kile ${ }^{1}$, Regina M. Carelli²,3, and R. Mark \\ Wightman $1,3,{ }^{*}$ \\ ${ }^{1}$ Department of Chemistry, University of North Carolina at Chapel Hill, Chapel Hill, North Carolina \\ 27599-3290, USA \\ ${ }^{2}$ Department of Psychology, University of North Carolina at Chapel Hill, Chapel Hill, North \\ Carolina 27599-3290, USA \\ ${ }^{3}$ Neuroscience Center, University of North Carolina at Chapel Hill, Chapel Hill, North Carolina \\ 27599-3290, USA
}

\section{Abstract}

Fast-scan cyclic voltammetry (FSCV) at carbon-fiber microelectrodes has been used to demonstrate that sub-second changes in catecholamine concentration occur within the nucleus accumbens (NAc) shell during motivated behaviors, and these fluctuations have been attributed to rapid dopamine signaling. However, FSCV cannot distinguish between dopamine and norepinephrine, and caudal regions of the NAc shell receive noradrenergic projections. Therefore, in the present study, we examined the degree to which norepinephrine contributes to catecholamine release within rostral and caudal portion of NAc shell. Analysis of tissue content revealed that dopamine was the major catecholamine detectable in the rostral NAc shell, whereas both dopamine and norepinephrine were found in the caudal subregion. To examine releasable catecholamines, electrical stimulation was used to evoke release in anesthetized rats with either stimulation of the medial forebrain bundle, a pathway containing both dopaminergic and noradrenergic projections to the NAc, or the ventral tegmental area/substantia nigra, the origin of dopaminergic projections. The catecholamines were distinguished by their responses to different pharmacological agents. The dopamine autoreceptor blocker, raclopride, as well as the monoamine and dopamine transporter blockers, cocaine and GBR 12909, increased evoked catecholamine overflow in both the rostral and caudal NAc shell. The norepinephrine autoreceptor blocker, yohimbine, and the norepinephrine transporter blocker, desipramine, increased catecholamine overflow in the caudal NAc shell without significant alteration of evoked responses in the rostral NAc shell. Thus, the neurochemical and pharmacological results show that norepinephrine signaling is restricted to caudal portions of the NAc shell. Following raclopride and cocaine or raclopride and GBR 12909, robust catecholamine transients were observed within the rostral shell but these were far less apparent in the caudal NAc shell, and they did not occur following yohimbine and desipramine. Taken together, the data demonstrate that catecholamine signals in the rostral NAc shell detected by FSCV are due to change in dopamine transmission.

\section{(C) 2010 IBRO. Published by Elsevier Ltd. All rights reserved}

*Corresponding Author: R. Mark Wightman, Ph.D. Department of Chemistry Caudill 339 University of North Carolina Chapel Hill, NC, 27599-3290, USA Tel : +1 (919) 962-1472 Fax : +1 (919) 962-2388 rmw@unc.edu.

Publisher's Disclaimer: This is a PDF file of an unedited manuscript that has been accepted for publication. As a service to our customers we are providing this early version of the manuscript. The manuscript will undergo copyediting, typesetting, and review of the resulting proof before it is published in its final citable form. Please note that during the production process errors may be discovered which could affect the content, and all legal disclaimers that apply to the journal pertain. 


\section{Keywords}

norepinephrine; dopamine; rostral and caudal nucleus accumbens shell; carbon-fiber microelectrode; medial forebrain bundle; ventral tegmental area/substantia nigra

Dopamine transmission within the nucleus accumbens (NAc) shell, a small region of the basal forebrain, is involved in information processing that mediates reward. Because of the role of dopamine in addiction and motivated behavior (Wise 2002; Di Chiara 1995; Aragona et al. 2008; Owesson-White et al. 2008), there have been extensive studies of dopamine transmission within this region. In our laboratories, we have used fast-scan cyclic voltammetry (FSCV) with a carbon-fiber microelectrode to correlate real-time dopamine transmission in the rostral NAc shell during associative learning and intake of drugs of abuse (Owesson-White et al. 2008; Phillips et al. 2003; Aragona et al. 2009). Dopamine was identified by the similarity of the cyclic voltammogram recorded in vivo with in vitro calibrations for dopamine. The cyclic voltammogram for dopamine is distinct from all neurochemicals that have been tested except norepinephrine (Baur et al. 1988; Heien et al. 2003). However, the cyclic voltammograms for dopamine and norepinephrine are virtually identical (Heien et al. 2004; Park et al. 2009), and thus independent confirmation of the specific catecholamine detected is required.

The dense dopaminergic innervation of the NAc shell is primarily from the cell bodies that originated in the ventral tegmental area (VTA). Anatomical studies have revealed that the NAc shell also receives a noradrenergic input to caudal portions of this structure (Berridge et al. 1997; Schroeter et al. 2000; Delfs et al. 1998). These noradrenergic inputs originate primarily from the A2 cell group in the nucleus tractus solitarius (NTS) (Delfs et al. 1998) and A6 cell group in the locus coeruleus (Berridge et al. 1997). The neurons from the NTS project through the ventral noradrenergic bundle $(\mathrm{VNB})$ and the medial forebrain bundle (MFB) to the NAc shell. The neurons from the locus coeruleus project through the dorsal noradrenergic bundle (DNB) and the MFB to the NAc shell. Importantly, both noradrenergic projections to the NAc primarily terminated within the caudal NAc shell.

Immunohisotchemical studies suggest that the rostral NAc shell receives little noradrenergic innervation (Berridge et al. 1997; Schroeter et al. 2000; Delfs et al. 1998), however, interpretation of cyclic voltammetric data with respect to the specific catecholamine detected requires that the dopamine/norepinephrine distribution is understood in more detail.

In the current study, we characterized catecholamine (dopamine and norepinephrine) content and overflow in both the medial rostral and caudal regions of the NAc shell. Because there is no delineating feature that defines the division of the medial rostral shell from the medial caudal shell, a variety of stereotaxic coordinates have been used by various groups (Heidbreder \& Feldon 1998; Hajnal \& Norgren 2004). We defined the medial rostral shell as the region of the NAc that extends from 1.45 to $1.90 \mathrm{~mm}$ anterior of bregma. The medial caudal NAc shell is defined here as the region from 0.70 to $1.20 \mathrm{~mm}$ anterior of bregma. Catecholamine release in anesthetized rats was evoked by electrical stimulation of the MFB, a fiber bundle that contains the majority of both the noradrenergic and dopaminergic fibers that project to the NAc shell. The other region stimulated was the VTA/substantia nigra (VTA/SN), a region that contains dopaminergic neurons and through which passes a portion of the VNB (Park et al. 2009; Ungerstedt 1971). The combined anatomical, neurochemical, and pharmacological characterization show that the major catecholamine released in the rostral NAC shell is dopamine whereas a mixture of dopamine and norepinephrine is released in the caudal NAc shell. 


\section{Materials and methods}

\section{Animals}

Adult male Sprague-Dawley rats (320-400g) were purchased from Charles Rivers (Wilmington, MA) and housed in temperature and humidity controlled rooms with ad libitum food and water with a 12/12 hr light/dark cycle. All procedures for handling and caring for the laboratory animals were in accordance with the NIH Guide for Care and Use of Laboratory Animals and were approved by the Institutional Animal Care and Use Committee of the University of North Carolina at Chapel Hill.

\section{Surgery}

Rats were anesthetized with urethane $(1.5 \mathrm{mg} / \mathrm{kg})$ and immobilized in a stereotaxic frame (David Kopf Instruments, Tujunga, CA). Temperature was maintained at $37{ }^{\circ} \mathrm{C}$ with a heating pad (Harvard Apparatus, Holliston, MA). Small holes on the skull were drilled for reference $(\mathrm{Ag} / \mathrm{AgCl})$ and stimulating electrodes as well as the carbon-fiber microelectrodes. The dura mater was punctured, carefully removed, and a single carbon-fiber microelectrode was lowered into the rostral (AP $+1.7 \mathrm{~mm}, \mathrm{ML}+0.8 \mathrm{~mm}$, DV $6.0-8.0 \mathrm{~mm}$ from bregma) or caudal (AP + $1.0 \mathrm{~mm}, \mathrm{ML}+0.9 \mathrm{~mm}$, DV $6.0-8.0 \mathrm{~mm}$ from bregma) NAc shell, coordinates taken from the atlas of (Paxinos \& Watson 2007). $\mathrm{An} \mathrm{Ag} / \mathrm{AgCl}$ reference electrode was placed in the contralateral cortex, and it was secured with dental cement. Electrical stimulation was accomplished with a bipolar, stainless-steel electrode $(0.2 \mathrm{~mm}$ in diameter, Plastics One, Roanoke, VA) insulated to the tip. The tips of the bipolar electrode were separated by $\sim 1.0 \mathrm{~mm}$. It was placed into the MFB (AP $-4.0 \mathrm{~mm}, \mathrm{ML}+1.4 \mathrm{~mm}, \mathrm{DV}$ $8.0-9.0 \mathrm{~mm}$ ) or the VTA/SN (AP $-5.2 \mathrm{~mm}, \mathrm{ML}+1.0 \mathrm{~mm}$, DV 8.0-9.0 mm).

\section{Electrical stimulation}

Computer-generated stimulus trains, (NL 800A, Neurolog, Medical Systems Corp., Great Neck, NY, U.S.A.), were optically isolated from the electrochemical system. The trains consisted of biphasic pulses ( $300 \mu \mathrm{A}, 2 \mathrm{~ms}$ each phase) with stimulation frequencies between 10 and $60 \mathrm{~Hz}$ applied through the bipolar electrode. Unless noted otherwise, the number of stimulus pulses was 24 . The time interval between electrical stimulations was 4 or $5 \mathrm{~min}$ to ensure reproducible catecholamine concentrations were released with each stimulation (Park et al. 2009).

\section{Voltammetric procedures}

Glass-encased, cylindrical carbon-fiber microelectrodes and $\mathrm{Ag} / \mathrm{AgCl}$ reference electrodes were prepared as described previously (Cahill et al. 1996). T-650 carbon fibers (5.1 $\mu \mathrm{m}$ in nominal diameter, Thornel, Amoco Corp., Greenville, SC) with an exposed length of $75-$ $100 \mu \mathrm{m}$ were used. Fast-scan cyclic voltammetry was computer-controlled and has been described in detail previously (Heien et al. 2003). A triangular scan $(-0.4$ to $+1.3 \mathrm{~V}, 400 \mathrm{~V} / \mathrm{s})$ was repeated every $100 \mathrm{~ms}$. Data was digitized and stored on a computer using software written in LABVIEW (National Instruments). Background-subtracted cyclic voltammograms were obtained by digitally subtracting voltammograms collected during stimulation from those collected during baseline recording. Voltammetric responses were viewed as color plots with the abscissa as voltage, the ordinate as acquisition time, and the current encoded in color (Michael et al. 1998). Temporal responses were determined by monitoring the current at the peak oxidation potential for dopamine in successive voltammograms or by principal component regression (Heien et al. 2005) as noted in the text. The current was converted to concentration based on calibration curves obtained after the in vivo experiment with known concentrations of dopamine in vitro. 


\section{Histology}

At the end of experiments, electrode placements were verified by stereotaxically lowering a tungsten electrode to the original position of the carbon-fiber microelectrode or directly with the carbon-fiber microelectrodes as described earlier (Garris \& Wightman 1994b; Park et al. 2009). When the carbon-fiber microelectrode ( 27 of 57 electrodes used in this study) was used to lesion the brain, this precluded postcalibration of the electrode sensitivity and instead, we used a postcalibration factor $(9.3 \pm 0.5 \mathrm{nA} / \mu \mathrm{M}$ for dopamine $)$, based on the average response obtained from more than 10 electrodes. The average geometric area of these electrodes (average length $=81.3 \mu \mathrm{m}$, diameter $=5.1 \mu \mathrm{m}$ ) was $1323 \mu \mathrm{m}^{2}$. Thus the sensitivity factor for the T650 carbon-fibers used in this work was $6.9 \pm 0.3 \mathrm{pA} /\left(\mu \mathrm{M} \cdot \mu \mathrm{m}^{2}\right)$.

A lesion was made at the recording site by applying constant current ( $20 \mu \mathrm{A}$ for $10 \mathrm{~s}$ ) to the tungsten or carbon-fiber electrodes. Brains were removed from the skull and stored in $10 \%$ formaldehyde for at least 3 days, and coronally sectioned into $40-50 \mu \mathrm{m}$ thick slices with a cryostat. The sections mounted on slides were stained with $0.2 \%$ thionin, and coverslipped before viewing under a light microscope.

\section{High performance liquid chromatography (HPLC)}

HPLC analysis of tissue content of catecholamines followed previously published procedures (Park et al. 2009). Briefly, the brain of an anesthetized rat was rapidly removed and placed on ice. Coronal brain slices $(500 \mu \mathrm{m}$ thick) were prepared in ice cold artificial cerebral spinal fluid (aCSF) using a Lancer Vibratome (World Precision Instruments, Sarasota, Fl.). The slice containing the rostral NAc shell was adjacent to the slice containing the caudal NAc shell. The dorsal shell region in these slices was dissected on a dry stainless steel surface while taking care to avoid inclusion of the adjacent NAc core and ventral pallidum. The resultant tissue was wet weighed in a pre-tared volume of $200 \mu \mathrm{L} 0.1 \mathrm{~N}$ $\mathrm{HClO}_{4}$ containing $1 \mu \mathrm{M}$ hydroquinone (HQ) and homogenized with a sonic dismembrator (Fisher Sci., Model 60, Pittsburgh, PA, USA). The sample was then centrifuged at $6000 \mathrm{~g}$ for $10 \mathrm{~min}$ and the supernatant was removed and filtered using a $0.2-\mu \mathrm{m}$ syringe microfilter (Millex-LG). Injections (10 $\mu \mathrm{L})$ were made onto a reverse phase column $(\mathrm{C}-18,5 \mu \mathrm{m}, 4.6 \times$ $250 \mathrm{~mm}$, Waters symmetry 300). The mobile phase (prepared in HPLC grade water) contained $0.1 \mathrm{M}$ citric acid, $1 \mathrm{mM}$ hexyl sodium sulfate, $0.1 \mathrm{~mm}$ EDTA, and $10 \%$ methanol $(\mathrm{pH} 3.5)$ at a flow rate of $1 \mathrm{~mL} / \mathrm{min}$. Catecholamines were detected with a thin-layer radial electrochemical cell (BASi, West Lafayette, IN, USA) at $700 \mathrm{mV}$ versus a $\mathrm{Ag} / \mathrm{AgCl}$ reference electrode. Catecholamine standards were prepared from $10 \mathrm{mM}$ stock solutions in $0.1 \mathrm{~N} \mathrm{HClO}_{4}$. A Labview stripchart recorder program (Jorgenson Lab, UNC-CH) was used for data collection through home built electronic equipment. The ratio of the peak area of the analyte to that of the internal standard (HQ) was used to calculate the amount of catecholamine in the original tissue sample.

\section{Drugs and reagents}

All chemicals and drugs were reagent-quality and were used without additional purification. Drugs were obtained from Sigma-Aldrich (St. Louis, MO, USA). In vitro dopamine postcalibration of carbon-fiber microelectrodes was done in a Tris buffer solution at $\mathrm{pH} 7.4$ containing $15 \mathrm{mM}$ Tris, $140 \mathrm{mM} \mathrm{NaCl}, 3.25 \mathrm{mM} \mathrm{KCl}, 1.2 \mathrm{mM} \mathrm{CaCl}_{2}, 1.25 \mathrm{mM} \mathrm{NaH}_{2} \mathrm{PO}_{4}$, $1.2 \mathrm{mM} \mathrm{MgCl}_{2}$, and $2.0 \mathrm{mM} \mathrm{Na}_{2} \mathrm{SO}_{4}$ in double distilled water (Mega Pure System, Corning Glasswork, Corning, NY). Desipramine- $\mathrm{HCl}$, cocaine- $\mathrm{HCl}$, raclopride- $\mathrm{HCl}$, and yohimbine$\mathrm{HCl}$ were dissolved in saline. GBR $12909-\mathrm{HCl}$ was dissolved in a small volume of distilled water and diluted with saline. Injected volumes were $0.6 \mathrm{ml} / \mathrm{kg}$ and were given intraperitoneally (i.p.). 


\section{Data analysis}

Clampfit 8.1 as part of pCLAMP 8.1 software package (Axon Instruments, Foster City, CA, USA) was used to analyze time values such as $\mathrm{t}_{\max }$ and $\mathrm{t}_{1 / 2}$ and signal amplitude values according to procedures described in the literature (Park et al. 2007). $t_{\max }$ is the time to reach the maximum concentration and $\mathrm{t}_{1 / 2}$, was taken as the time to descend from its maximum value to half of that value. $[\mathrm{CA}]_{\max }$ is the maximal evoked catecholamine concentration. Catecholamine transients were identified by principal component regression algorithm written into the Tar Heel CV software as descried earlier (Heien et al. 2004; Keithley et al. 2009). Catecholamine transients were defined as anything greater than five times the root-mean-square noise level and were analyzed for frequency, amplitude, and duration using Mini Analysis Software (Synaptosoft, Decatur, GA, USA). Data are represented as mean \pm S.E.M. and ' $n$ ' values indicating the number of rats. Statistical significance of changes in $[\mathrm{CA}]_{\max }$ and $\mathrm{t}_{1 / 2}$ values before and after drugs was determined using a $2 \times 2 \times 2$ repeated measures ANOVA followed by a $t$-test post-hoc analysis with a Bonferroni correction for multiple comparison for brain region (rostral and caudal shell), drugs (yohimbine and yohimbine + desipramine, raclopride and raclopride + cocaine or raclopride + cocaine and raclopride + GBR 12909) and stimulation region (MFB and VTA/ $\mathrm{SN})$ as the three variables. Statistical significance of $[\mathrm{CA}]_{\max }, \mathrm{t}_{1 / 2}$, and $\mathrm{t}_{\max }$ values was determined using a $2 \times 2$ repeated ANOVA followed by a $t$-test post-hoc analysis with a Bonferroni correction for multiple comparison for brain region (rostral and caudal shell) and stimulation region (MFB and VTA/SN) as the two variables. Statistical analysis employed GraphPad Software version 4.0 (San Diego, CA, USA) or SPSS 14.0 software (SPPS, Chicago, IL). Differences were considered significant when the $P$ value was $<0.05$.

\section{Results}

\section{Catecholamine content of the rostral and caudal NAc shell}

The rostral and caudal NAc shell were dissected from fresh brains and their catecholamine content determined by HPLC (Table 1). The dopamine tissue content in the rostral and caudal NAc regions was not significantly different $(t=0.99, d . f .=25, P=0.33)$. Dopamine was a major catecholamine in the rostral NAc shell. Only a very low amount of norepinephrine was found (norepinephrine was present in one of fifteen samples from 5 rats), but both dopamine and norepinephrine were present in significant amounts in the caudal NAc shell. The ratio of norepinephrine to dopamine content for the caudal NAc shell was $\sim 1$ to 3 . Serotonin was not detected in either subregion.

\section{Electrically stimulated catecholamine release in the rostral NAc shell}

Catecholamine release was measured by fast-scan cyclic voltammetry in the rostral NAc shell during electrical stimulation $(60 \mathrm{~Hz}, 24$ pulses, $300 \mu \mathrm{A})$ of either the VTA/SN or the MFB. When the stimulating electrode was above or below these stimulation sites, catecholamine release in the NAc shell was not observed. Representative examples of the time courses are shown in Figure 1A. With either location of the stimulating electrode, catecholamine release began immediately upon stimulus initiation, reached a similar maximum, and the concentration returned to its initial value after the stimulation. Cyclic voltammograms recorded at the maximum were identical to those for catecholamines recorded after in vivo use (Figure 1A, right panel), with the maximum oxidation current observed at $\sim+0.65 \mathrm{~V}$ and the peak for the reduction of the electrochemically formed quinone at $\sim-0.2 \mathrm{~V}$ on the reverse scan. Shown in the right panel of Figure 1B is a photograph of a brain slice used for histological verification of the location of the carbonfiber microelectrode. The black arrow points to the location of the electrode tip when the lesion was made. The lesion sites for all from carbon-fiber electrodes in the rostral NAc shell are shown in are shown in Supplementary Figure 1, left panel. 
To characterize the distribution of catecholamine release sites in the rostral NAc shell, release evoked by $60 \mathrm{~Hz}$ stimulation was measured at different depths with fast-scan cyclic voltammetry with stimulating electrodes placed either in the MFB or VTA/SN. Figure 1B (left panel) shows the coronal plane in which measurements were made (AP $+1.8 \mathrm{~mm}$ ) and the approximate electrode track is shown by the solid line. The carbon-fiber microelectrode was lowered within the rostral NAc shell in 200-300 $\mu \mathrm{m}$ increments beginning at $3.3 \mathrm{~mm}$ from the skull, with release measured at each location. A plot of $[\mathrm{CA}]_{\max }$ normalized to the maximum value observed along the track is shown in Figure 1C. Robust release was not observed until a depth of $5.3 \mathrm{~mm}$ below the skull. Release reached a maximum at a depth of $6.5 \mathrm{~mm}$ and decreased to negligible values at $8.0 \mathrm{~mm}$. Responses from misplaced electrodes (determined via histology to be located in the caudate-putamen $(\mathrm{CPu})$ near the ventricle or in the NAc core) were discarded.

\section{Electrically stimulated catecholamine release in the caudal NAc shell}

Identical experiments were conducted in the caudal NAc shell. Electrical stimulation of the MFB (example in Figure 2A) resulted in catecholamine release as identified by the cyclic voltammograms (Figure 2A, right panel). The catecholamine concentration remained elevated for a longer time than in the rostral NAc shell. When release in the caudal NAc shell was evoked with VTA/SN stimulation, its amplitude was about one third of that evoked by MFB stimulation. A histological record of one carbon-fiber microelectrode placement in the caudal NAc shell (AP $+1.0 \mathrm{~mm}$ ) is shown in Figure 2B (right panel, black arrow indicates the lesion site).

The vertical distribution of release sites in this region was also characterized with both MFB and VTA/SN stimulation. The approximate vertical track is shown in Figure 2B (left panel). The measured $[\mathrm{CA}]_{\max }$, normalized to the maximum value observed along the track, is shown in Figure 2C. With MFB stimulation, release began to become apparent at $\sim 5.5 \mathrm{~mm}$ below the skull. Maximal release was observed between 6.2 and $6.8 \mathrm{~mm}$ and then it decreased. With VTA/SN stimulation, release was much lower and reached a maximum at about $6.4 \mathrm{~mm}$ below the skull.

\section{Comparison of catecholamine overflow in the rostral and caudal NAc shell}

Catecholamine release and its time course in the rostral and caudal NAc shell was quantitated and compared in the sites where maximal release was observed (Table 2). Evoked $[\mathrm{CA}]_{\max }$ in the rostral NAc shell was statistically identical with stimulation of the MFB or VTA/SN. The time to reach the maximum concentration $\left(\mathrm{t}_{\max }\right)$ was $\sim 0.6 \mathrm{~s}$ in the rostral NAc shell with stimulation in either location, $0.2 \mathrm{~s}$ longer than the duration of the 60 $\mathrm{Hz}$ stimulation $(0.4 \mathrm{~s})$. The response time of the electrode is $\sim 0.2 \mathrm{~s}$, accounting for the delay (Owesson-White et al. 2008). Following the stimulation, the time to return to half of the maximal value $\left(\mathrm{t}_{1 / 2}\right)$ in the rostral NAc shell was approximately the same with stimulation in each region. Since the descending part of the curves is due to neuronal uptake (Giros et al. 1996), the similar clearance time suggests that the same transporter is responsible for the removal of catecholamine in this region.

$[\mathrm{CA}]_{\max }$ in the caudal NAc shell was significantly lower than that in the rostral NAc shell $\left(F_{1,38}=1459, P<0.0001\right)$. In the caudal NAc shell, $[\mathrm{CA}]_{\max }$ was approximately 3 times greater when evoked in the MFB than when evoked in the VTA/SN $(t=6.7, d . f .=15, P<$ $0.0001)$. The values of $t_{\max }$ in the caudal NAc shell were statistically longer than those measured in the rostral NAc shell $\left(F_{1,41}=11.35, P<0.01\right)$. Similarly, the $\mathrm{t}_{1 / 2}$ values in the caudal NAc shell were statistically longer than the values measured in the rostral NAc shell $\left(F_{1,41}=12.27, P<0.005\right)$. The delayed $\mathrm{t}_{\max }$, coupled with the higher values of $\mathrm{t}_{1 / 2}$, indicates uptake is weaker in the caudal NAc shell allowing greater diffusional transport of 
catecholamines from their release site (Venton et al. 2003). Again, the similarity of the $\mathrm{t}_{1 / 2}$ values in the caudal NAc shell suggests the transporter responsible for clearance is independent of the stimulation site.

\section{Influence of dopamine and norepinephrine drugs on extracellular catecholamine evoked by VTA/SN and MFB stimulation in rostral and caudal NAc shell}

The tissue content measurements (Table 1) show that norepinephrine tissue content is very low within the rostral NAc shell, and thus the catecholamine responses in this region would be expected to be due to dopamine. However, those in caudal NAc shell could be due to either dopamine, norepinephrine, or both. To provide evidence for the specific catecholamine(s) measured in each region, pharmacological agents were employed. For dopamine, the D2 receptor antagonist, raclopride $(2 \mathrm{mg} / \mathrm{kg})$, and the monoamine transporter blocker, cocaine $(15 \mathrm{mg} / \mathrm{kg})$, were used to enhance release and reduce uptake respectively. For norepinephrine, the norepinephrine $\alpha 2$-adrenoceptor antagonist, yohimbine $(6 \mathrm{mg} / \mathrm{kg})$, and the norepinephrine transporter blocker, desipramine (desmethylimipramine, $15 \mathrm{mg} / \mathrm{kg}$ ), were used to enhance release and reduce uptake respectively. The doses selected were based on our prior work in the $\mathrm{CPu}$, a dopamine rich region, and the ventral bed nucleus of the stria terminalis, a norepinephrine rich region (Park et al. 2009).

The responses in the rostral NAc shell evoked by MFB or VTA/SN stimulation $(60 \mathrm{~Hz}, 24$ pulses) were unchanged $30 \mathrm{~min}$ following administration of yohimbine and desipramine (representative example in Figure $3 \mathrm{~A}$ ). Neither $[\mathrm{CA}]_{\max }$ nor $\mathrm{t}_{1 / 2}$, a measure of the clearance rate, were affected by the norepinephrine drugs in the rostral NAc shell (Table 3 ). In contrast, raclopride and cocaine increased the responses in the rostral NAc shell (representative example in Figure 3B). Raclopride significantly increased both $[\mathrm{CA}]_{\max }$ and $t_{1 / 2}$ (Table 3 ) and these increases were enhanced by cocaine. The increases were found irrespective of the stimulus location (MFB or VTA/SN). Thus, although evoked catecholamine in the rostral NAc shell is insensitive to drugs that alter norepinephrine neurotransmission, it is sensitive to drugs that act on dopaminergic terminals.

In the caudal NAc shell, catecholamine signaling was altered by both dopaminergic and noradrenergic drugs in contrast to the rostral NAc shell. The response in the caudal NAc shell region evoked by the MFB stimulation showed a modest increase 30 min after injection of yohimbine (representative result in Figure 4A, left, data from multiple animals summarized in Table 3). Desipramine administered after yohimbine, further increased the evoked response (representative example in Figure 4A, left). Raclopride and cocaine also increased the responses in the caudal NAc shell evoked by either MFB or VTA/SN stimulation (representative example Figure 4B, data from multiple animals summarized in Table 3). Following these dopaminergic drugs, both $[\mathrm{CA}]_{\max }$ and $\mathrm{t}_{1 / 2}$ were increased in the caudal NAc shell when evoked by either stimulation site (Table 3 ). With stimulation of the VTA/SN, the evoked catecholamine response in the caudal NAc shell was not changed following yohimbine alone, but did increase with the combination of desipramine and yohimbine (representative example in Figure 4A, right, Table 3). This combination of noradrenergic drugs led to significant increases in $[\mathrm{CA}]_{\max }$ and $\mathrm{t}_{1 / 2}$ in the caudal NAc shell with both stimulation sites (Table 3$)$ in contrast to the rostral NAc shell $\left(F_{1,44}=55.42, \mathrm{P}<\right.$ 0.0001 for $[\mathrm{CA}]_{\max }$, and $F_{1,43}=14.43, \mathrm{P}<0.005$ for $\mathrm{t}_{1 / 2}$ ). The combination of raclopride and cocaine increased $t_{1 / 2}$ of the response evoked by either the MFB or by the VTA/SN stimulation more in the caudal NAc shell than in the rostral NAc shell (Figure 4B, Table 3) $\left(F_{1,42}=10.40, P<0.01\right)$. Thus in the caudal NAc shell, catecholamine transmission is sensitive to both noradrenergic and dopaminergic drugs.

In this study, cocaine was used as a catecholamine uptake inhibitor because the effects of cocaine seeking and self-administration on dopamine neurotransmission were previously 
studied in the NAc (Phillips et al. 2003; Owesson-White et al. 2009). However, cocaine is not a selective DAT inhibitor. Therefore, we also studied the effect of GBR 12909, a selective DAT inhibitor, on catecholamine release evoked by MFB stimulation in the rostral and caudal NAc shell. GBR 12909, administered after raclopride, further increased the response in the rostral and caudal NAc shell region evoked by the MFB stimulation (representative result in Supplementary Fig. 2, data from multiple animals summarized in Table 3). There were no significant differences in the increases of $[\mathrm{CA}]_{\max }$ and $\mathrm{t}_{1 / 2}$ by raclopride followed by GBR 12909 between rostral and caudal NAc shell. The effects of GBR 12909 on evoked dopamine occur more slowly than with cocaine (Espana et al. 2008; Budygin et al. 2000). Therefore, comparison of the GBR 12909 and cocaine effects after administration of raclopride can differ because of their different time courses of action.

\section{Catecholamine transient release in the rostral and caudal NAc shell after administration of raclopride and cocaine}

Figure 5 shows catecholamine fluctuations $15 \mathrm{~min}$ before and after raclopride and cocaine in both the rostral and caudal NAc shell. The fluctuations before drug in the color plots represent the electrical noise of the system. Following administration of both raclopride ( 2 $\mathrm{mg} / \mathrm{kg}$ ) and cocaine $(15 \mathrm{mg} / \mathrm{kg})$, fluctuations in the voltammetric responses were observed (Figure 5B) while there was no detectable signal before the administration of the drugs (Figure 5A). The color plots, and cyclic voltammograms extracted from them (Figure 5B) clearly reveal that these are transient increases in catecholamines that occur without electrical stimulation. This was confirmed by principal component regression of the voltammograms (Heien et al. 2005). These catecholamine fluctuations are similar to the dopamine transients that we previously reported in the $\mathrm{CPu}$ of anesthetized rats following similar drug treatments (Venton \& Wightman 2007). As in the CPu, dopamine autoreceptor blockade alone was insufficient to evoke transients in anesthetized rats. However, $5 \mathrm{~min}$ following a subsequent injection of cocaine, transients were induced that reached a maximum amplitude within $15 \mathrm{~min}$ and continued for 20 to $30 \mathrm{~min}$. Transients were observed following the dopaminergic drugs in the rostral NAc shell in 9 out of 12 rats while only 4 of 16 rats showed weak transients in the caudal NAc shell. Drug-evoked transients were not observed following administration of the noradrenergic drugs, yohimbine $(6 \mathrm{mg} /$ $\mathrm{kg})$ and desipramine $(15 \mathrm{mg} / \mathrm{kg})$, in either the rostral or caudal NAc shell.

The maximal concentration of transients following cocaine and raclopride within the caudal NAc shell, $0.05 \pm 0.01 \mu \mathrm{M}$ ( $\mathrm{n}=4$ rats), was much lower than in the rostral NAc shell, $0.17 \pm$ $0.02 \mu \mathrm{M}(\mathrm{n}=9$ rats, $t=4.7, d . f .=11, P=0.0006)$. The average transient frequency was $0.35 \mathrm{~Hz}(10.5 \pm 0.5$ transients per $30 \mathrm{sec}, \mathrm{n}=8)$ for rostral NAc shell. In addition, the maximal concentration of transient $(0.14 \pm 0.03 \mu \mathrm{M}, \mathrm{n}=5)$ and average transient frequency $(0.38 \mathrm{~Hz}, 11.5 \pm 0.4$ transients per $30 \mathrm{sec}, \mathrm{n}=5)$ following GBR 12909 and raclopride in the rostral NAc shell were not significantly different from the values following cocaine and raclopride (Supplementary Fig. 2). It was difficult to compile a frequency average for transients in the caudal NAc shell due to the absence of catecholamine transients in most rats. The drug-induced transients in the rostral NAc shell were observed at similar depths (6.0-7.5 $\mathrm{mm}$ from the skull surface) as stimulated release (compare Supplementary Figure 3 with Figures $1 \mathrm{C}$ and 2C).

\section{Discussion}

Here, we examined the evoked release of catecholamines in two NAc subregions with fastscan cyclic voltammetry. The sensor employed, the carbon-fiber microelectrode, has micron dimensions allowing investigation of these two subregions that are only separated by $\sim 800$ $\mu \mathrm{m}$. Catecholamine release was evoked by either stimulation of the MFB, a major ascending pathway that contains both dopaminergic and noradrenergic neurons (Ungerstedt 1971), or 
the VTA/SN region. Stimulation in the latter region activates dopamine cell bodies (Garris \& Wightman 1994a) as well as the VNB that passes through these regions (Ungerstedt 1971). The major finding of this work is that catecholamine release in the rostral NAc shell is predominantly from dopaminergic neurons whereas in the caudal NAc shell release of both catecholamines can be evoked. This finding is consistent with the neurochemical content of the subregions of the NAc shell. Our findings also show that measurable fluctuations in extracellular dopamine arise following combined administration of a dopamine autoreceptor antagonist and a catecholamine uptake inhibitor, cocaine, or a dopamine uptake inhibitor, GBR 12909. In contrast, simultaneous inhibition of noradrenergic autoreceptors and uptake does not evoke measurable transients in anesthetized rats. Our data are consistent with previous immunohistochemistry studies have shown that noradrenergic neurons innervate the caudal NAc shell to a greater degree than the rostral region (Delfs et al. 1998), whereas dopaminergic neurons originating in the VTA project to both subregions (Ikemoto 2007; Swanson 1982). The current study not only provides more definitive evidence that catecholamine transmission within the rostral NAc shell measured by FSCV is due primarily to dopamine transmission, but also indicates that norepinephrine signaling is restricted to the caudal NAc shell. This is of interest because it has been suggested that the noradrenergic projection in the caudal NAc shell may modulate processes associated with stress, behavior state, or reinforcement via its actions within this region (Hajnal \& Norgren 2004).

\section{Extracellular measurements of catecholamines in the NAc shell}

Our chromatographic analysis of tissue content (Table 1) confirmed that dopamine is the predominant catecholamine in the rostral NAc shell whereas $\sim 30 \%$ of the catecholamine in the caudal NAc shell was norepinephrine. Extracellular norepinephrine and dopamine measurements by microdialysis within the NAc also showed that dopamine is the predominant catecholamine in the NAc core whereas both norepinephrine and dopamine are present in dialysate from the NAc shell (McKittrick \& Abercrombie 2007; Hajnal \& Norgren 2004;Carboni et al. 2006). In this study, our voltammetric measurements confirmed that stimulation of ascending pathways evokes catecholamine release in both the rostral and caudal NAc shell. Stimulation at $60 \mathrm{~Hz}$ at both of the sites investigated evokes a rapid increase in catecholamines throughout the NAc shell. $[\mathrm{CA}]_{\max }$ in the caudal NAc shell was significantly lower than that in the rostral NAc shell although tissue content is similar. This discrepancy between $[\mathrm{CA}]_{\max }$ and dopamine content may reflect our failure to dissect exactly the same nuclei each time. Furthermore, norepinephrine release has been shown to be a smaller fraction of total stores than is dopamine release (Garris \& Wightman 1995). Thus, tissue content is also not always proportional to catecholamine transmission in the terminal region. Consistent with our evoked release, extracellular dopamine has been shown to have a rostral to caudal gradient (Heidbreder \& Feldon 1998). The time to reach the maximum concentration $\left(t_{\text {max }}\right)$ in the rostral NAc shell is $0.2 \mathrm{~s}$ longer than the stimulus duration, a consequence of the finite response time of the electrode (Owesson-White et al. 2008). The clearance rates (measured as $t_{1 / 2}$,Table 2 ) were slower in the caudal NAc shell than in the rostral region. Consistent with this, the dopamine transporter (DAT) is less densely distributed in the caudal NAc shell than in the rostral region (Pilotte et al. 1996). The norepinephrine transporter (NET) exhibits a similar distribution to that of the noradrenergic terminals in both the NAc shell of rats (Schroeter et al. 2000) and humans (Tong et al. 2007). Thus, in the rostral NAc shell, uptake is primarily controlled by the DAT whereas in the caudal region both NET and DAT contribute to the observed clearance.

To establish the nature of the catecholamine detected we used pharmacological agents. In prior work we and others have shown that release from dopaminergic terminals is enhanced by antagonists of the dopamine autoreceptor and prolonged by inhibition of the DAT, but is 
insensitive to drugs that act on noradrenergic neurons (Park et al. 2009; Carboni et al. 2006; Gobert et al. 1998; Palij \& Stamford 1992).

Conversely, release from noradrenergic terminals is insensitive to dopamine specific drugs but is enhanced by antagonists of the norepinephrine autoreceptor and inhibition of NET (Park et al. 2009; Gobert et al. 1998). Here, such pharmacological studies confirmed that dopamine was the predominant species released in the rostral NAc shell, an observation consistent with the microdialysis, anatomical, and tissue content studies. In contrast, release in the caudal NAc shell was affected by both a norepinephrine autoreceptor antagonist and an inhibitor of the NET as well as the dopaminergic drugs. Therefore, we conclude that stimulated release in the caudal NAc shell is a mixture of dopamine and norepinephrine.

\section{Catecholamine projections to the rostral and caudal NAc shell}

To evoke dopamine release in the rostral NAc shell, we chose the MFB and the VTA/SN region for placement of the stimulating electrode. Stimulation of both regions resulted in similar amounts of dopamine release in the rostral NAc shell, suggesting the same neurons were stimulated in each case. This is likely the case because VTA dopaminergic neurons project through the MFB en route to terminal regions (Ungerstedt 1971; Ikemoto 2007). To evoke catecholamine release in the caudal NAc shell, we stimulated the same two regions but the amounts released were quite different. As well as dopamine release, norepinephrine release might be expected with stimulation of the VTA/SN region because the ventral noradrenergic bundle (VNB) originating from A2 and A1 neurons passes through this region (Ungerstedt 1971). We have shown previously that electrical stimulation of the VTA/SN activates at least a portion of the VNB because norepinephrine release was detected in the ventral bed nucleus of the stria terminalis (Park et al. 2009). Release in the caudal NAc shell was greater with MFB stimulation indicating that more catecholamine terminals were activated. These could include the fibers of the DNB that also pass through the MFB (Berridge et al. 1997).

The data obtained in the caudal NAc shell cannot be used to distinguish the amount of norepinephrine and dopamine that are released because the cyclic voltammograms for dopamine and norepinephrine are virtually identical (Heien et al. 2004; Park et al. 2009). Confounding the pharmacological data is the fact that NET can modulate a portion of the extracellular dopamine because it has a greater affinity for dopamine than the DAT (Moron et al. 2002). However, the results in the rostral NAc shell can be interpreted with much more confidence. The data clearly show that dopamine is by far the predominant catecholamine detected. Thus, this work validates our prior measurements of dopamine concentration fluctuations during intracranial self-stimulation (Owesson-White et al. 2008) and during cocaine administration (Aragona et al. 2009).

\section{Dopamine transients occur following combined inhibition of dopamine uptake and autoreceptors}

A key feature of dopamine neurotransmission are the naturally occurring dopamine concentration transients that are observed in awake animals (Wightman et al. 2007). They occur as a consequence of burst firing of dopaminergic neurons that can be evoked by activation of NMDA receptors in the VTA (Sombers et al. 2009). However, in deeply anesthetized animals these are rarely seen (Venton \& Wightman 2007), a finding that is consistent with the reduction in burst firing that occurs in anesthetized animals (Fa et al. 2003). Previously we showed that dopamine transients can occur within the $\mathrm{CPu}$ of an anesthetized rat following administration of a D2 receptor antagonist and a catecholamine transporter blocker (Venton \& Wightman 2007). The results shown here indicate that dopamine transients of similar origin can occur in the NAc shell. Electrophysiological 
studies of VTA dopaminergic studies have shown that the combined regimen of cocaine and a D2 antagonist lead to increased burst firing and slow rhythmic oscillations in the firing rate of dopamine neurons in anesthetized rats (Shi et al. 2004). Even though the anesthesia, dose of drugs used, and route of administration differed, the frequency of the cell firing oscillations $(0.74 \mathrm{~Hz})$ was remarkably similar to the frequency $(0.35 \mathrm{~Hz})$ of the dopamine concentration transients reported here. Inhibition of autoreceptors and uptake remove two of the key, negative-feedback components that regulate dopaminergic neurons. Removal of negative feedback frequently leads to oscillatory behavior. Note, however, that similar inhibition of noradrenergic negative feedback does not cause oscillatory behavior.

Sequential administration of a noradrenergic autoreceptor antagonist and noradrenergic uptake inhibitor do not give rise to transients in the caudal NAc shell or the bed nucleus of the stria terminalis (Park et al. 2009) even though there is sufficient norepinephrine present in those regions to contribute to robust electrically evoked responses.

\section{Conclusion}

The present results show that norepinephrine is regulated in the caudal NAc shell by norepinephrine autoreceptors and uptake transporters. This result suggests that dopaminergic and noradrenergic transmission within the caudal NAc shell may play significantly different roles in regulating the behavioral and physiologic responses associated with drug abuse, physical stressors and other rewarding and aversive stimuli, compared to the rostral NAc shell.

\section{Supplementary Material}

Refer to Web version on PubMed Central for supplementary material.

\section{Acknowledgments}

We thank Khristy Fontillas for providing technical assistance and thank Richard B. Keithley and Dr. Nii Addy for supporting data analysis. This work was supported by NIH (NS 15841).

\section{comprehensive list of abbreviations}

$\begin{array}{ll}\text { NAc } & \text { nucleus accumbens } \\ \text { FSCV } & \text { fast-scan cyclic voltammetry } \\ \text { MFB } & \text { medial forebrain bundle } \\ \text { VTA/SN } & \text { ventral tegmental area/substantia nigra } \\ \text { DNB } & \text { dorsal noradrenergic bundle } \\ \text { DAT } & \text { dopamine transporter } \\ \text { NET } & \text { norepinephrine transporter }\end{array}$

\section{References}

Aragona BJ, Cleaveland NA, Stuber GD, Day JJ, Carelli RM, Wightman RM. Preferential enhancement of dopamine transmission within the nucleus accumbens shell by cocaine is attributable to a direct increase in phasic dopamine release events. J Neurosci. 2008; 28:8821-8831. [PubMed: 18753384]

Aragona BJ, Day JJ, Roitman MF, Cleaveland NA, Mark Wightman R, Carelli RM. Regional specificity in the real-time development of phasic dopamine transmission patterns during 
acquisition of a cue-cocaine association in rats. Eur J Neurosci. 2009; 30:1889-1899. [PubMed: 19912327]

Baur JE, Kristensen EW, May LJ, Wiedemann DJ, Wightman RM. Fast-scan voltammetry of biogenic amines. Anal Chem. 1988; 60:1268-1272. [PubMed: 3213946]

Berridge CW, Stratford TL, Foote SL, Kelley AE. Distribution of dopamine beta-hydroxylase-like immunoreactive fibers within the shell subregion of the nucleus accumbens. Synapse. 1997; 27:230-241. [PubMed: 9329158]

Budygin EA, Kilpatrick MR, Gainetdinov RR, Wightman RM. Correlation between behavior and extracellular dopamine levels in rat striatum: comparison of microdialysis and fast-scan cyclic voltammetry. Neurosci Lett. 2000; 281:9-12. [PubMed: 10686403]

Cahill PS, Walker QD, Finnegan JM, Mickelson GE, Travis ER, Wightman RM. Microelectrodes for the measurement of catecholamines in biological systems. Anal Chem. 1996; 68:3180-3186. [PubMed: 8797378]

Carboni E, Silvagni A, Vacca C, Di Chiara G. Cumulative effect of norepinephrine and dopamine carrier blockade on extracellular dopamine increase in the nucleus accumbens shell, bed nucleus of stria terminalis and prefrontal cortex. J Neurochem. 2006; 96:473-481. [PubMed: 16336224]

Delfs JM, Zhu Y, Druhan JP, Aston-Jones GS. Origin of noradrenergic afferents to the shell subregion of the nucleus accumbens: anterograde and retrograde tract-tracing studies in the rat. Brain Res. 1998; 806:127-140. [PubMed: 9739125]

Di Chiara G. The role of dopamine in drug abuse viewed from the perspective of its role in motivation. Drug Alcohol Depend. 1995; 38:95-137. [PubMed: 7671769]

Espana RA, Roberts DC, Jones SR. Short-acting cocaine and long-acting GBR-12909 both elicit rapid dopamine uptake inhibition following intravenous delivery. Neuroscience. 2008; 155:250-257. [PubMed: 18597947]

Fa M, Mereu G, Ghiglieri V, Meloni A, Salis P, Gessa GL. Electrophysiological and pharmacological characteristics of nigral dopaminergic neurons in the conscious, head-restrained rat. Synapse. 2003; 48:1-9. [PubMed: 12557266]

Garris PA, Wightman RM. Different kinetics govern dopaminergic transmission in the amygdala, prefrontal cortex, and striatum: an in vivo voltammetric study. J Neurosci. 1994a; 14:442-450. [PubMed: 8283249]

Garris PA, Wightman RM. In vivo voltammetric measurement of evoked extracellular dopamine in the rat basolateral amygdaloid nucleus. J Physiol. 1994b; 478:239-249. [PubMed: 7965845]

Garris, PA.; Wightman, RM. Regional differences in dopamine release, uptake, and diffusion measured by fast-scan cyclic voltammetry: Voltammetric Methods in Brain Systems. Humana Press; Totowa, NJ: 1995.

Giros B, Jaber M, Jones SR, Wightman RM, Caron MG. Hyperlocomotion and indifference to cocaine and amphetamine in mice lacking the dopamine transporter. Nature. 1996; 379:606-612. [PubMed: 8628395]

Gobert A, Rivet JM, Audinot V, Newman-Tancredi A, Cistarelli L, Millan MJ. Simultaneous quantification of serotonin, dopamine and noradrenaline levels in single frontal cortex dialysates of freely-moving rats reveals a complex pattern of reciprocal auto- and heteroreceptor-mediated control of release. Neuroscience. 1998; 84:413-429. [PubMed: 9539213]

Hajnal A, Norgren R. Sucrose sham feeding decreases accumbens norepinephrine in the rat. Physiol Behav. 2004; 82:43-47. [PubMed: 15234588]

Heidbreder C, Feldon J. Amphetamine-induced neurochemical and locomotor responses are expressed differentially across the anteroposterior axis of the core and shell subterritories of the nucleus accumbens. Synapse. 1998; 29:310-322. [PubMed: 9661249]

Heien ML, Johnson MA, Wightman RM. Resolving neurotransmitters detected by fast-scan cyclic voltammetry. Anal Chem. 2004; 76:5697-5704. [PubMed: 15456288]

Heien ML, Khan AS, Ariansen JL, Cheer JF, Phillips PE, Wassum KM, Wightman RM. Real-time measurement of dopamine fluctuations after cocaine in the brain of behaving rats. Proc Natl Acad Sci U S A. 2005; 102:10023-10028. [PubMed: 16006505] 
Heien ML, Phillips PE, Stuber GD, Seipel AT, Wightman RM. Overoxidation of carbon-fiber microelectrodes enhances dopamine adsorption and increases sensitivity. Analyst. 2003; 128:1413-1419. [PubMed: 14737224]

Ikemoto S. Dopamine reward circuitry: two projection systems from the ventral midbrain to the nucleus accumbens-olfactory tubercle complex. Brain Res Rev. 2007; 56:27-78. [PubMed: 17574681]

Keithley RB, Heien ML, Wightman RM. Multivariate concentration determination using principal component regression with residual analysis. Trac-Trend Anal Chem. 2009; 28:1127-1136.

McKittrick CR, Abercrombie ED. Catecholamine mapping within nucleus accumbens: differences in basal and amphetamine-stimulated efflux of norepinephrine and dopamine in shell and core. J Neurochem. 2007; 100:1247-1256. [PubMed: 17241132]

Michael D, Travis ER, Wightman RM. Color images for fast-scan CV measurements in biological systems. Anal. Chem. 1998; 70:586A-592A.

Moron JA, Brockington A, Wise RA, Rocha BA, Hope BT. Dopamine uptake through the norepinephrine transporter in brain regions with low levels of the dopamine transporter: evidence from knock-out mouse lines. J Neurosci. 2002; 22:389-395. [PubMed: 11784783]

Owesson-White CA, Ariansen J, Stuber GD, Cleaveland NA, Cheer JF, Wightman RM, Carelli RM. Neural encoding of cocaine-seeking behavior is coincident with phasic dopamine release in the accumbens core and shell. Eur J Neurosci. 2009; 30:1117-1127. [PubMed: 19735286]

Owesson-White CA, Cheer JF, Beyene M, Carelli RM, Wightman RM. Dynamic changes in accumbens dopamine correlate with learning during intracranial self-stimulation. Proc Natl Acad Sci U S A. 2008; 105:11957-11962. [PubMed: 18689678]

Palij P, Stamford JA. Real-time monitoring of endogenous noradrenaline release in rat brain slices using fast cyclic voltammetry: 1. Characterisation of evoked noradrenaline efflux and uptake from nerve terminals in the bed nucleus of stria terminalis, pars ventralis. Brain Res. 1992; 587:137146. [PubMed: 1525644]

Park J, Galligan JJ, Fink GD, Swain GM. Differences in sympathetic neuroeffector transmission to rat mesenteric arteries and veins as probed by in vitro continuous amperometry and video imaging. $\mathrm{J}$ Physiol. 2007; 584:819-834. [PubMed: 17761778]

Park J, Kile BM, Wightman RM. In vivo voltammetric monitoring of norepinephrine release in the rat ventral bed nucleus of the stria terminalis and anteroventral thalamic nucleus. Eur J Neurosci. 2009; 30:2121-2133. [PubMed: 20128849]

Paxinos, G.; Watson, C. The Rat Brain in Stereotaxic Coordinates. Elsevier Inc.; Burlington: 2007.

Phillips PE, Stuber GD, Heien ML, Wightman RM, Carelli RM. Subsecond dopamine release promotes cocaine seeking. Nature. 2003; 422:614-618. [PubMed: 12687000]

Pilotte NS, Sharpe LG, Rountree SD, Kuhar MJ. Cocaine withdrawal reduces dopamine transporter binding in the shell of the nucleus accumbens. Synapse. 1996; 22:87-92. [PubMed: 8822482]

Schroeter S, Apparsundaram S, Wiley RG, Miner LH, Sesack SR, Blakely RD. Immunolocalization of the cocaine- and antidepressant-sensitive 1-norepinephrine transporter. J Comp Neurol. 2000; 420:211-232. [PubMed: 10753308]

Shi WX, Pun CL, Zhou Y. Psychostimulants induce low-frequency oscillations in the firing activity of dopamine neurons. Neuropsychopharmacology. 2004; 29:2160-2167. [PubMed: 15257309]

Sombers LA, Beyene M, Carelli RM, Wightman RM. Synaptic overflow of dopamine in the nucleus accumbens arises from neuronal activity in the ventral tegmental area. J Neurosci. 2009; 29:17351742. [PubMed: 19211880]

Swanson LW. The projections of the ventral tegmental area and adjacent regions: a combined fluorescent retrograde tracer and immunofluorescence study in the rat. Brain Res Bull. 1982; 9:321-353. [PubMed: 6816390]

Tong J, Hornykiewicz O, Furukawa Y, Kish SJ. Marked dissociation between high noradrenaline versus low noradrenaline transporter levels in human nucleus accumbens. J Neurochem. 2007; 102:1691-1702. [PubMed: 17484728]

Ungerstedt U. Stereotaxic mapping of the monoamine pathways in the rat brain. Acta Physiol Scand Suppl. 1971; 367:1-48. [PubMed: 4109331] 
Venton BJ, Wightman RM. Pharmacologically induced, subsecond dopamine transients in the caudateputamen of the anesthetized rat. Synapse. 2007; 61:37-39. [PubMed: 17068772]

Venton BJ, Zhang H, Garris PA, Phillips PE, Sulzer D, Wightman RM. Real-time decoding of dopamine concentration changes in the caudate-putamen during tonic and phasic firing. $\mathrm{J}$ Neurochem. 2003; 87:1284-1295. [PubMed: 14622108]

Wightman RM, Heien ML, Wassum KM, et al. Dopamine release is heterogeneous within microenvironments of the rat nucleus accumbens. Eur J Neurosci. 2007; 26:2046-2054. [PubMed: 17868375]

Wise RA. Brain reward circuitry: insights from unsensed incentives. Neuron. 2002; 36:229-240. [PubMed: 12383779] 


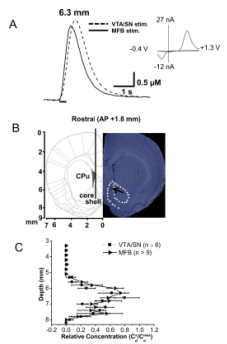

Figure 1.

Electrically evoked catecholamine responses measured in the rostral NAc shell. (A) Representative maximal catecholamine responses in the rostral NAc shell were evoked by MFB (solid line) or VTA/SN (dotted line) stimulation $(60 \mathrm{~Hz}, 24$ pulses). The bars under the current traces denote the period of electrical stimulation. Insets: background-subtracted cyclic voltammograms measured during the evoked responses. (B) Solid line in the schematic diagram illustrate the approximate path of the carbon-fiber microelectrodes through the rostral NAc shell (left). The location of the carbon-fiber microelectrode tip in the rostral NAc shell (right) was visualized by the electrolytic lesion (black arrow). The coronal section is adapted from the atlas of Paxinos and Watson (2007). (C) Maximal stimulated release during electrical stimulation measured in the rostral NAc shell as the carbon-fiber microelectrode was lowered in small increments through the regions shown in B. The relative response is the concentration at particular depth $\left(C_{d}{ }^{x}\right)$ divided by the maximum concentration $\left(\mathrm{C}_{\mathrm{d}}{ }^{\mathrm{max}}\right)$. The catecholamine response in the rostral NAc shell was evoked by MFB or VTA/SN stimulation $(60 \mathrm{~Hz}, 24$ pulses). Abbreviations used: $\mathrm{CPu}$, caudate-putamen. 

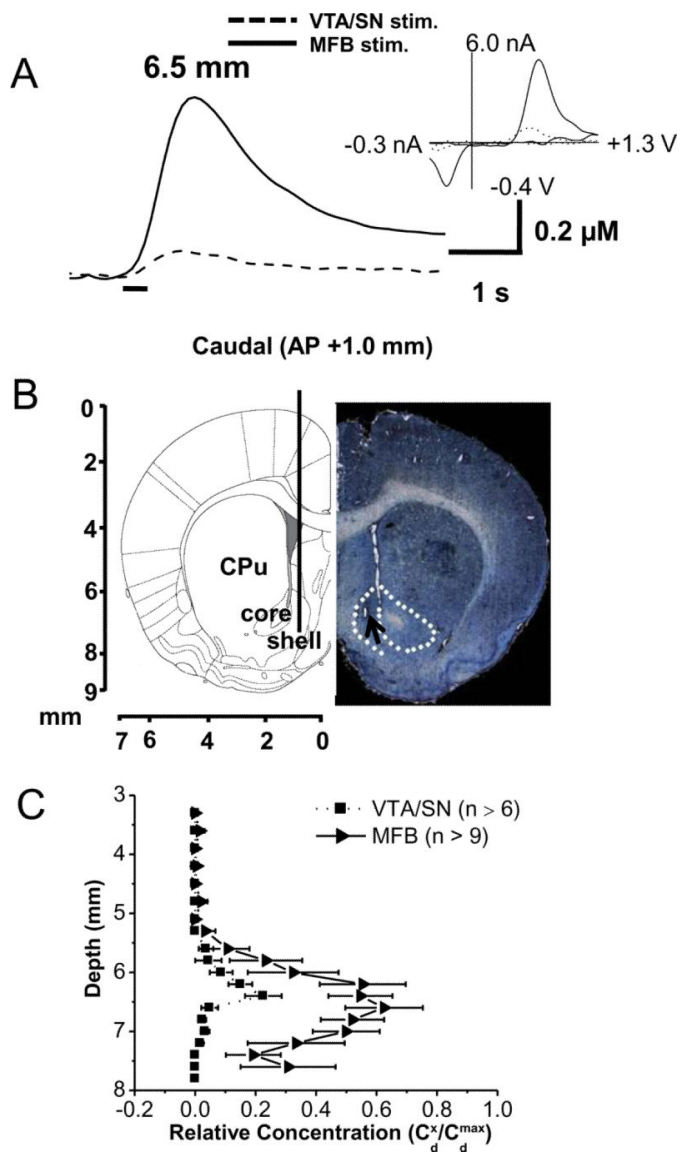

Figure 2.

Electrically evoked catecholamine responses measured in the caudal NAc shell. (A) Representative maximal catecholamine responses at the peak current for catecholamines in the caudal NAc shell. The bars under the current traces denote the period of electrical stimulation $(60 \mathrm{~Hz}, 24$ pulses). Insets: background-subtracted cyclic voltammograms measured during the evoked responses. (B) Solid line in the schematic diagram illustrate the approximate path of the carbon-fiber microelectrodes in the caudal NAc shell (left). The placement of the carbon-fiber microelectrode tip in the caudal NAc shell (right) was visualized by the electrolytic lesion (black arrow). The coronal section is adapted from the atlas of Paxinos and Watson (2007). (C) Maximal stimulated release during electrical stimulation measured in the caudal NAc shell as the carbon-fiber microelectrode was lowered in small increments through the regions shown in $\mathrm{B}$. The relative response is the response at particular depth $\left(\mathrm{C}_{\mathrm{d}}{ }^{\mathrm{x}}\right)$ divided by the maximum concentration $\left(\mathrm{C}_{\mathrm{d}}{ }^{\mathrm{max}}\right)$. The catecholamine response in the caudal NAc shell was evoked by MFB or VTA/SN stimulation $(60 \mathrm{~Hz}, 24$ pulses $)$. Abbreviations used: $\mathrm{CPu}$, caudate-putamen. 


\section{Rostral NAc Shell}

A
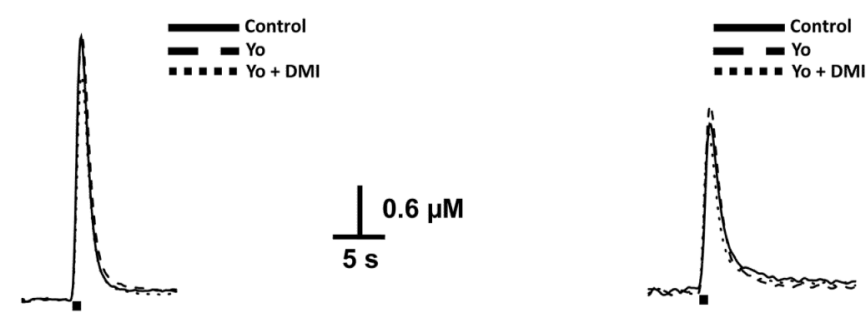

B

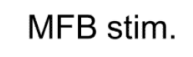

VTA/SN stim.
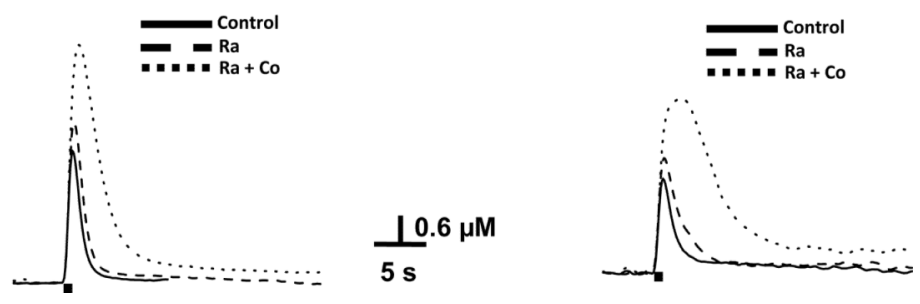

Figure 3.

Effect of yohimbine (Yo, $5 \mathrm{mg} / \mathrm{kg}$ ), desipramine (DMI, $15 \mathrm{mg} / \mathrm{kg}$ ), raclopride (Ra, $2 \mathrm{mg} / \mathrm{kg}$ ) and cocaine $(\mathrm{Co}, 15 \mathrm{mg} / \mathrm{kg})$ on catecholamine overflow in the rostral NAc shell.

Representative recordings of extracellular catecholamine in the rostral NAc shell evoked by MFB (left) or VTA/SN stimulation (right) in the presence of (A) Yo (---) and Yo + DMI (...), (B) $\mathrm{Ra}(---)$ and $\mathrm{Ra}+\mathrm{Co}(\ldots)$ at $60 \mathrm{~Hz}$ with 24 pulses. The bars under the current traces indicate the period of electrical stimulation. 


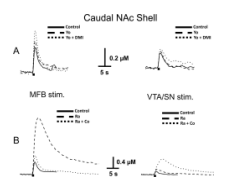

Figure 4.

Effect of yohimbine (Yo, $5 \mathrm{mg} / \mathrm{kg}$ ), desipramine (DMI, $15 \mathrm{mg} / \mathrm{kg}$ ), raclopride (Ra, $2 \mathrm{mg} / \mathrm{kg}$ ) and cocaine $(\mathrm{Co}, 15 \mathrm{mg} / \mathrm{kg})$ on catecholamine overflow in the caudal NAc shell.

Representative recordings of extracellular catecholamine in the rostral shell evoked by MFB stimulation (left) or VTA/SN (right) in the presence of (A) Yo (---) and Yo + DMI (...), (B) $\mathrm{Ra}(---)$ and $\mathrm{Ra}+\mathrm{Co}(\ldots)$ at $60 \mathrm{~Hz}$ with 24 pulses. The bars under the current traces indicate the period of electrical stimulation. 


\section{Caudal NAc Shell}
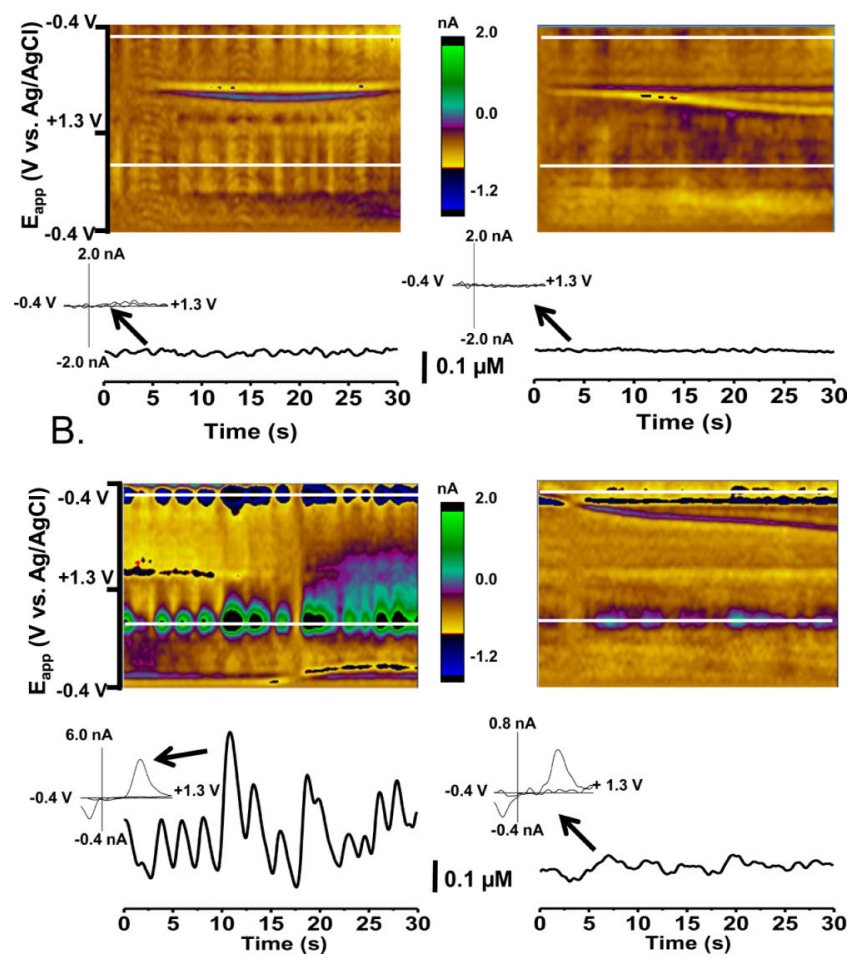

Figure 5.

Drug induced catecholamine concentration transients in the rostral and caudal NAc shell after raclopride (2 mg/kg, i.p.) and cocaine (15 mg/kg, i.p.). Two-dimensional color plot representation of the background-subtracted cyclic voltammograms collected over $30 \mathrm{sec}$ (A) before and (B) following administration of drugs in the rostral and caudal NAc shell. Catecholamine concentration changes are apparent in the color plots $(\mathrm{B})$ at the potential for its oxidation $(\sim 0.65 \mathrm{~V})$ and its reduction $(-0.2 \mathrm{~V})$. Principal component regression was used to extract the time course of the catecholamine concentration transients (lower traces in A and B). Times are indicated by the vertical bars. Inset: Cyclic voltammograms recorded at the time indicated by the arrows were identical to those for a catecholamine. 
Table 1

Monoamine content in the NAc shell. Values represent the mean \pm S.E.M.

\begin{tabular}{ccc}
\hline NAc Shell & Rostral $(\mathbf{A P}+\mathbf{1 . 9}$ to $\mathbf{1 . 4 m m})(\boldsymbol{\mu g} / \mathbf{g}, \mathbf{n}=\mathbf{1 5}$ samples $)$ & Caudal $(\mathbf{A P}+\mathbf{1 . 2}$ to $\mathbf{0 . 7} \mathbf{~ m m})(\boldsymbol{\mu g} \mathbf{g}, \mathbf{n}=\mathbf{~ 1 2}$ samples $)$ \\
\hline Norepinephrine & $0.04 \pm 0.04$ & $1.14 \pm 0.55^{*}$ \\
\hline Dopamine & $3.99 \pm 0.73$ & $3.09 \pm 0.57$ \\
\hline$*$ &
\end{tabular}


Table 2

Parameters measured during the electrically evoked $(300 \mu \mathrm{A}, 60 \mathrm{~Hz}, 24$ pulses $)$ catecholamine responses in the rostral and caudal NAc shell.

\begin{tabular}{ccccc}
\hline$(\mathbf{n} \geq 8)$ & \multicolumn{2}{c}{ CA in rostral shell } & \multicolumn{2}{c}{ CA in caudal shell } \\
\hline Stimulation & MFB & VTA/SN & MFB & VTA/SN \\
\hline$[\mathbf{C A}]_{\max } \boldsymbol{\mu M}$ & $2.00 \pm 0.26^{*}$ & $1.78 \pm 0.28^{*}$ & $0.65 \pm 0.06$ & $0.18 \pm 0.03$ \\
$\mathbf{t}_{\mathbf{m a x}}(\mathbf{s})$ & $0.65 \pm 0.02^{*}$ & $0.60 \pm 0.02^{*}$ & $0.83 \pm 0.07$ & $0.97 \pm 0.09$ \\
$\mathbf{t}_{\mathbf{1} / \mathbf{2}}(\mathbf{s})$ & $1.12 \pm 0.05^{*}$ & $1.01 \pm 0.04^{*}$ & $1.84 \pm 0.24$ & $1.52 \pm 0.17$ \\
\hline
\end{tabular}

$[\mathrm{CA}]_{\max }$ is the maximal evoked catecholamine concentration; $\mathrm{t}_{\max }$ is the time to reach to the peak response from the start of the stimulation,; $\mathrm{t} 1 / 2$ is the time required for catecholamine overflow to decay to $50 \%$ of the maximum. Values represent the mean \pm S.E.M.

${ }^{*}(P<0.05, t$-test with Bonferroni correction) indicates significantly different from caudal NAc shell. 


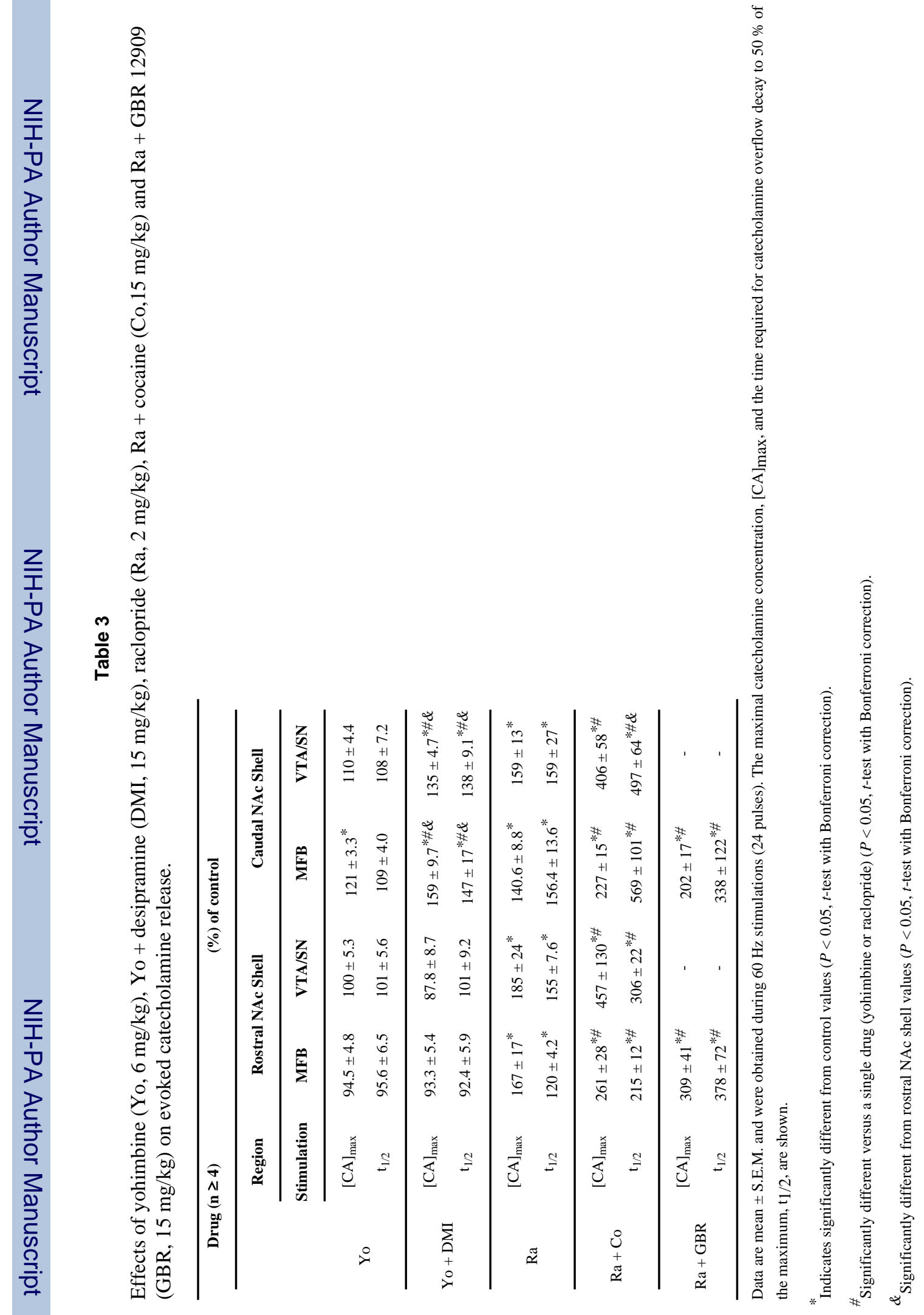

